\title{
Assessment of Understanding using Concept Map: A Novel Approach
}

\author{
Kumar R \\ Rajalakshmi Engineering College \\ Chennai \\ India
}

\author{
Sarukesi K \\ Hindustan University \\ Chennai \\ India
}

\author{
Uma G V \\ Anna University \\ Chennai \\ India
}

\begin{abstract}
Concept Map (CM) is a visual knowledge representation (KR) tool that represents concepts and the relationships among them. A concept is referred to the perceived regularity of objects or events. The concepts are used to form the nodes of the map and the relationships among these concepts form the edges. This tool provides a visual representation of a knowledge which will be very much useful for humans to understand better. This paper proposes a novel approach that analyzes the role of $\mathrm{CM}$ in knowledge assessment. The participants have been introduced with concept mapping technique and asked to map their understanding of the topics covered during the session. The results obtained after analysis are found to be encouraging to proceed for further studies.
\end{abstract}

\section{General Terms}

Concept Map, Knowledge Representation, Assessment

\section{Keywords}

Concept Map, Knowledge Representation, Assessment

\section{INTRODUCTION}

To make knowledge shareable, its representation is of interest. In the scientific, technical, business, administrative and educational setups, it is customary to record knowledge representation. Knowledge in Higher Education Institution (HEI) generally represented in the form of textbooks, reports, manual, compendiums, dossiers and other text documents. The problems associated are that they are mainly textual, difficult to keep up to date, difficult to locate or search and time consuming etc., With the advent of Information and Communication Technology (ICT) another form of KR is being done through the WWW i.e. Classical Web Sites and Wikis, blogs and forums etc., Even though the above methods contribute more towards $\mathrm{KR}$, there are issues with respect to maintenance efforts, and dynamic nature of the contents or methods. So, there is a need to identify a feasible and more flexible way of KR as a ready reference for the users.

KR can be described as a method for knowledge modeling, to create and to represent knowledge. These include the following processes Conceptualization, Collection of Concepts and Description of the relation between concepts. Knowledge Nets like Topic Maps, Concept Maps, Mind Maps, Ontologies and Semantic Nets have been used widely for representing knowledge in various fields. These nets are following a systematic approach and present knowledge in way both humans and machines understand well. Other than these nets, KR systems use many methods and languages like Logics, frames, XML and SGML have been used to represent the knowledge.

John D Novak [1] proposed CMs in 1970s to assess the understanding of subject knowledge of school students. A concept map is a node-arc diagram used as a method to represent knowledge. The nodes of the map represent the concepts and labeled arcs represent the relationships between two concepts, in the same way that a E-R diagram represents the entities and the relation among them of a database.

Measuring the understanding level of the learners of a program in stages will help to improve the quality of learning and to keep the class room live. This can be achieved by many approaches like by receiving feedback, by asking questions, by giving problems to solve. But choosing a right, flexible and suitable method to assess the understanding of the participants is challenging work. The flexibility of the CM encourages the researchers to use $\mathrm{CM}$ as a tool for evaluating the knowledge received by the participants. Novak [4] used CM to evaluate learning as well as the knowledge organization in the elementary class students. Julia and Carlos [11] proposed open, closed and semi-open concept mapping methods and used them for the assessment of learning.

This study was performed to know the impact of CMs in the learning environment. CM was introduced to a group of 23 participants and they were asked to take up a simple test. The test is designed to assess the understanding level of the participants using the CM.

This paper is organized as follows: section 2 discusses the related works. The research work conducted is described in section 3, section 4 explains the evaluation method adopted. Section 5 explains the results analysis, section 6 presents the observations and section 7 concludes the paper.

\section{RELATED WORKS}

$\mathrm{CM}$ is widely known as a visual knowledge representation tool. It has been used to present and represent knowledge in different fields. Novak [4] stated that concept maps tend to make the structure of a body of knowledge much more salient than other forms of knowledge representation for human users.

$\mathrm{CM}$ has been widely used in many fields to represent knowledge visually. A few examples are knowledge acquisition and knowledge modeling, teaching learning, design, software engineering, Natural Language Processing $\mathrm{CM}$ has been used as a teaching tool in various levels of educational institutions to give better understanding of the relationships between concepts. This also helps the students to correlate and map the new knowledge with previous knowledge during the learning process.

Novak[3] first used CM to assess the understanding and knowledge level of school students belonging to primary classes. Gul Takdemir and Nergiz Ercil Cagiltayet [7] used $\mathrm{CM}$ to introduce engineering course curriculum in engineering education institutions. Gupta et al. [5] used CMs for concept mapping in a web based tutorial for RF and Microwave course. 


\section{My Understanding of Concept Maps}

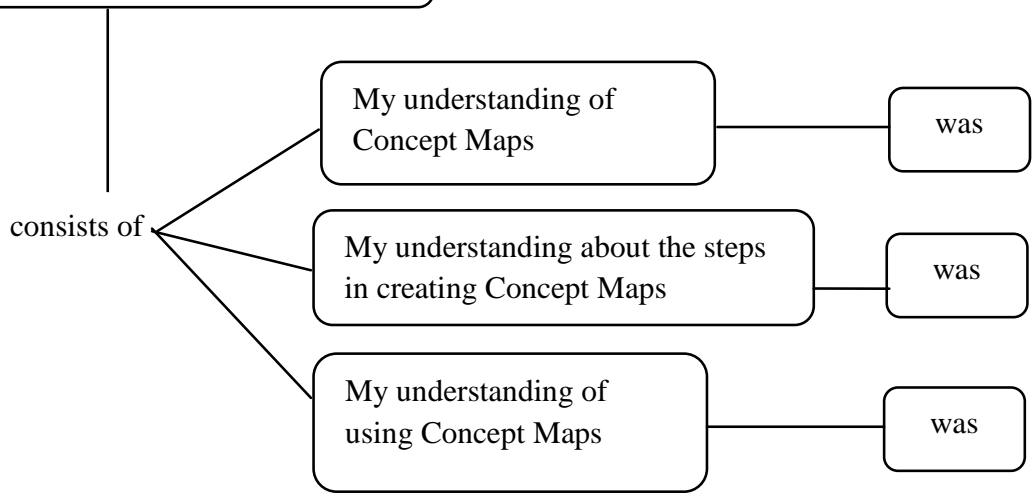

Figure. 1 A Concept Map as feedback form

Debopriyo Roy[6] emphasized the importance of using specific kinds of concept maps, such as ladders, in a technical writing class offered for computer science majors.

Mehmet Buldua and Nihal Buldub[10] used CM in the class room as an assessment tool for measuring the student satisfaction. Many others tried and used CM for teaching Grammar [9], Mathematics [12], Sportive Techniques [13] Science and Chemistry $[8,14]$ for meaningful learning. CMs are not only used as a learning tool but also as an evaluation tool, thus encouraging students to have a meaningful-mode of learning [11], [12],[13],[15]. CM was also used in linguistics and to represent knowledge at informal level, as well as at formal level [16]. Edwards et al., [17] reported that CMs were found effective in identifying both valid and invalid ideas held by students.

In addition many number of researchers have been using CM in various processes of the teaching and learning like as a teaching tool, an assessment tool, notes taking tool etc., Further to the above mentioned works, CMs have been used for notes taking, summarizing important key concepts and relationships, designing the Course Level Instruction, question answer systems other related applications.

\section{RESEARCH METHODLOGY}

The main objectives of this work are (i) to assess the understanding of the learners using the $\mathrm{CM}$ (ii) to observe the outcomes of the study while using $\mathrm{CM}$ as a KR tool. The basic ideas of concept mapping were introduced to the participants. The session was attended by 23 participants. A detailed lecture on the introduction to $\mathrm{CM}$ and ways to use the $\mathrm{CM}$ to represent knowledge was explained to them. Maps created by the authors were used to teach the topics of interest during the session. Then the participants were given hands on training towards creating maps on their own for a given topic. At the end of the session, a test was conducted on a specific topic covered during the session. The participants were asked to construct a concept map from the knowledge they acquired during the session. The question had been set up with only one seed node with which the map is to be constructed further.

The main advantage of using the seed node for constructing map is to allow the learners to construct freely as they feel. This will help the resource person to understand the perceptions of the learners on the topic discussed. Since only the seed node is given the learners may use any type of CM i.e. hierarchy or system or flowchart or spider whichever is applicable to construct the map. The map would certainly reflect the perceptions as they understand the concepts. The participants had shown interest and attempted to construct the maps well within the given time. Later it took hours to evaluate the maps to interpret them. Nearly 70 percent of the participants were done close to map created by the authors. Sometimes the resultant map may not be the same as the expert's map as there are chances for misconception. But this is one of the appropriate ways of performing an assessment to evaluate the understanding level of the learners in a continuous manner. Also this would help the lecturer to decide further proceedings as whether to continue with the next topic or repeat the previous topic.

Then feedback forms were supplied to all the participants. The feedback form was designed as a Concept Map questionnaire. The questions and corresponding responses were placed in the map as nodes and link (relationship) for each question is left incomplete (see Figure.1). The participants were asked to link the nodes to represent their opinion about the session. A five point scale was involved in the questionnaire as Excellent, Very Good, Good, Fair and Poor with points ranging from 5 to 1 respectively.

\section{EVALUATION OF MAPS}

The evaluation of the $\mathrm{CM}$ is a critical and tedious work. During the evaluation of maps, the concepts or nodes, lines and arrows, propositions or statements, layers and examples would be assessed by awarding points to them based on their validness. There considerable number of scoring methods proposed by many researchers. The maps constructed by the participants were evaluated based on Novak's structured evaluation method. The structured scoring method is devised as follows;

Each valid concept will be awarded with 1 point. Every valid link that connects two valid concepts will have 1 point. Similarly if the map is hierarchical, then hierarchy will also carry 1 point. Cross links between different concepts will carry 2 points each. Examples if any will be awarded with 1 point.

A map for the same topic chosen for test was created by the authors. The same was used as the key map (answer) to evaluate the map. The key map for the topic is presented in Figure. 2. By adopting this method the maps were evaluated and marks were awarded. It is necessary to record that considerable amount of time had been taken to evaluate the maps manually. 


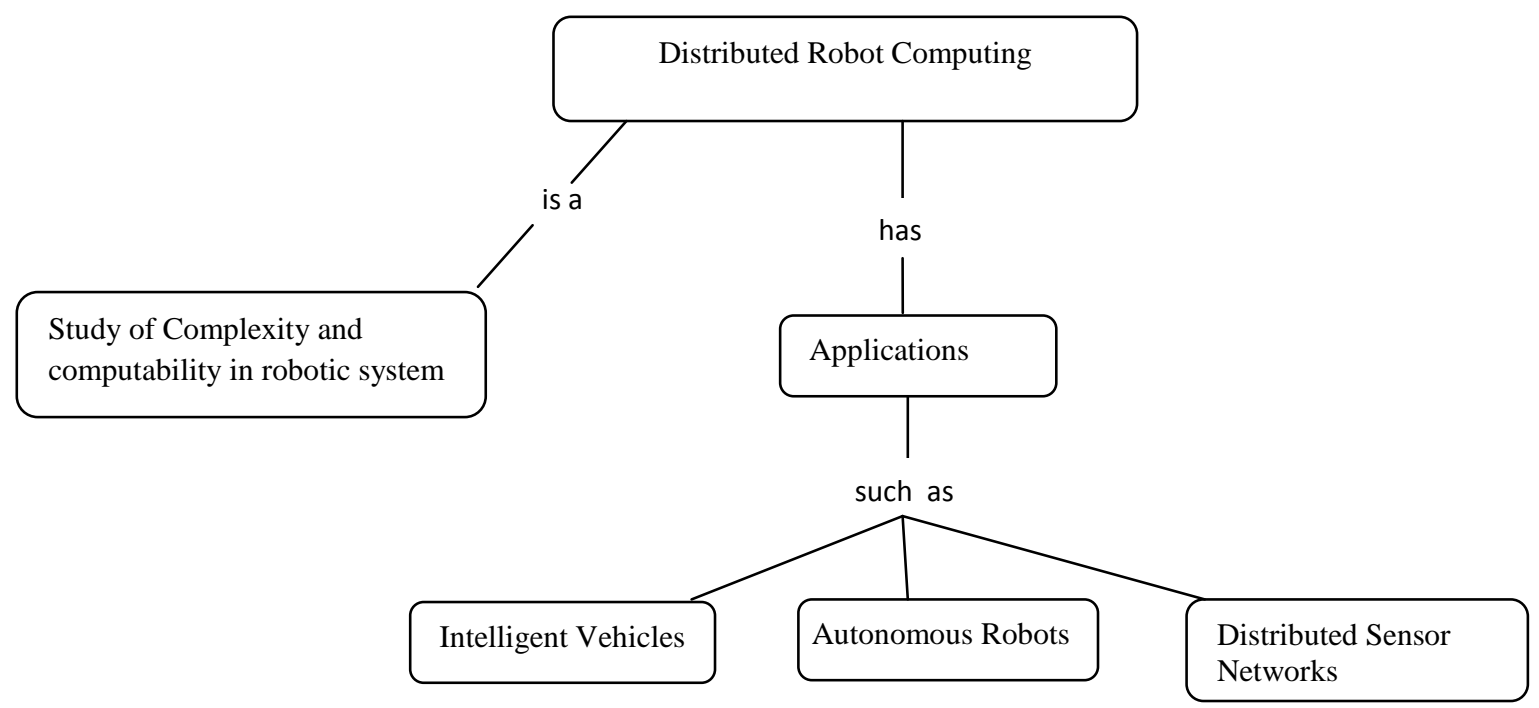

Figure. 2 Concept Map used as key map for evaluation

\section{ANALYSIS}

\subsection{Test Results}

Marks scored by all the participants are presented below (Table.1). The test marks were analyzed and the following were the observations from the analysis; about $26 \%$ of the participants scored 7 marks, 22\% participants scored 6 and 8 marks respectively, $17 \%$ of the participants had scored 5 marks and rest scored less than 5 marks. On the whole nearly $86 \%$ of the participants scored 5 and above. The summary of the marks is represented as a bar chart (Figure.3) below.

Table.1 Marks scored by participants

\begin{tabular}{|c|c|c|c|c|c|c|c|c|c|c|}
\hline Marks & 1 & 2 & 3 & 4 & 5 & 6 & 7 & 8 & 9 & 10 \\
\hline $\begin{array}{c}\text { No. of } \\
\text { Participants }\end{array}$ & 0 & 0 & 1 & 2 & 4 & 5 & 6 & 5 & 0 & 0 \\
\hline$\%$ & 0 & 0 & 4 & 8 & 17 & 22 & 26 & 22 & 0 & 0 \\
\hline
\end{tabular}

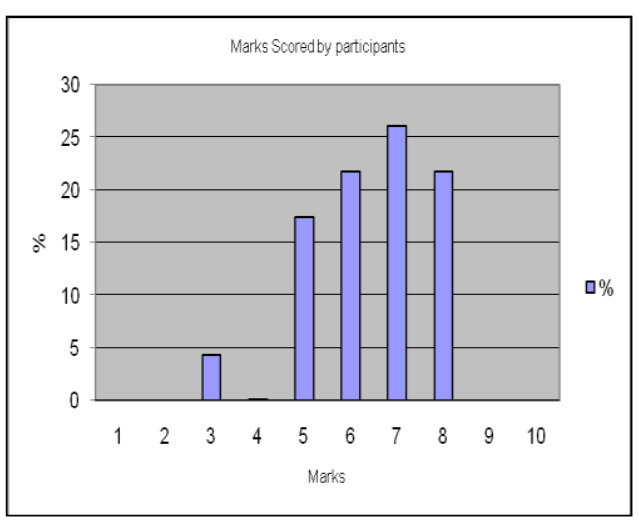

Figure. 3 Chart representing the marks

\subsection{Feedback Analysis}

The feedbacks from the participants were also interpreted and the scores for all three questions from each participant were calculated. The scores given by the participants question wise are displayed in the Table.2.

The feedback data is perceived as follows; among the 23 participants, about $60 \%$ of them stated that their understanding of the basic concepts of CM was good, about $78 \%$ of them stated that they their understanding of steps in creating maps was good and about $52 \%$ of them stated that their understanding of the applications of CM was good. The results were analyzed using the weighted average method and percentage method.

Table. 2 Feedback obtained from the participants

\begin{tabular}{|c|c|c|c|}
\hline Qn/Weight & A & B & C \\
\hline 1 & 0 & 0 & 0 \\
\hline 2 & 1 & 1 & 1 \\
\hline 3 & 14 & 18 & 12 \\
\hline 4 & 3 & 3 & 7 \\
\hline 5 & 5 & 1 & 3 \\
\hline
\end{tabular}

The responses were then used to create a chart. A bar chart representing the response of the participants is shown in Figure. 4. Among the 3 questions given, the choice 'Good' was opted by around $60 \%$ of the participants for question $a$, about $78 \%$ for question $b$ and $52 \%$ for question c. The choice Very Good has been opted for the given questions are respectively about $13 \%, 13 \%$ and $30 \%$. At the same time about $21 \%, 0.04 \%$ and $13 \%$ opted the choice Excellent for the questions respectively. This is giving a clear understanding that majority of the participants represented their satisfactory towards the introduction of concepts, their understanding of CMs and the understanding of steps in creating maps. 
The data collected through the feedback were first interpreted into excel with the equivalent weights assigned for each choice given. Then it was analyzed using the weighted average method. (see Table. 3).

The weighted average is one of the effective methods for ranking by which the rank of given objects can be found. This is done by calculating the weighted average using the weights assigned for each object using the formula;

$$
W A=\frac{\sum W i X i}{\sum X i}
$$

Where $\mathrm{W}$ is the weight applied and $\mathrm{X}$ is the number of participants who selected a specific choice concerned in the feedback.

From the weighted average calculated for each question, the rank for each question is arrived. The average values calculated are 5.4, 4.9 and 5.4 respectively for the questions (a), (b) and (c). It is observed that majority of the participants responded positively that the objective of introducing the concept maps was well received. The ranks can be interpreted as following: the questions a, $\mathrm{c}$ are ranked equally sharing the first place and $c$ is ranked as second place. From this it is perceived that the participants had agreed that they received the basics of CM well and they also understood the usage of maps in the class room as a KR tool which was evidenced in the test results. The results also gave an indication that the understanding of steps involved in creating $\mathrm{CM}$ is to be given more emphasis hence the need for more practice on creation of maps.

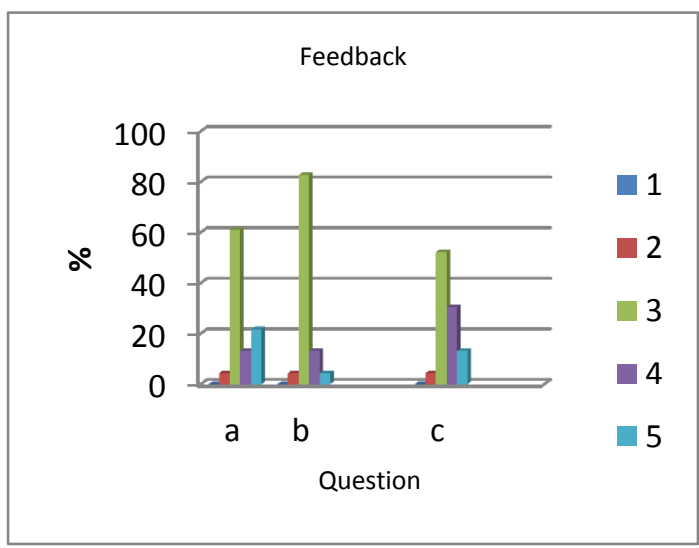

Figure. 4 chart for feedback analysis

\section{OBSERVATIONS}

Though the usage of CM in educational settings for various activities has been studied, proved as an effective tool, this study was performed for the participants who are not the native speakers of English but the learning medium is English. From the results obtained from the study the following were observed;

(a) $\mathrm{CM}$ has been accepted by $90 \%$ of the participants as an useful tool for learning.

(b) $60 \%$ of the participants were able to represent their understanding correctly, hence the effective role of $\mathrm{CM}$ as a $\mathrm{KR}$ tool was also observed.
Table. 3 Weighted Average calculated for the feedback

\begin{tabular}{|c|c|c|c|c|c|c|}
\hline $\begin{array}{c}\text { Qn/Marks / } \\
\text { No. of } \\
\text { Participants }\end{array}$ & $\mathbf{1}$ & $\mathbf{2}$ & $\mathbf{3}$ & $\mathbf{4}$ & $\mathbf{5}$ & Total \\
\hline A & 0 & 1 & 14 & 3 & 5 & 23 \\
\hline B & 0 & 1 & 18 & 3 & 1 & 23 \\
\hline C & 0 & 1 & 12 & 7 & 3 & 23 \\
\hline \multicolumn{7}{|c|}{ Weighted Average } \\
\hline v(a)*Weight & 0 & 2 & 42 & 12 & 25 & 5.4 \\
\hline $\mathrm{v}(\mathrm{b})^{*}$ Weight & 0 & 2 & 54 & 12 & 5 & 4.9 \\
\hline $\mathrm{v}(\mathrm{c})^{*}$ Weight & 0 & 2 & 36 & 28 & 15 & 5.4 \\
\hline
\end{tabular}

(c) The test results and feedback were correlated and it was observed that $87 \%$ of the participants scored above 6 marks and about $90 \%$ rated the session on creating maps was good. The degree of acceptance in both the contexts falls in a close range; hence this confirms that $\mathrm{CM}$ is an effective tool for KR.

Further, it is mandatory to record that few hours spent for the preparation of concept maps for teaching the topics as well as to evaluate maps and interpret their scores. There are potential research problems on the role of $\mathrm{CM}$ to assess the understanding and as a KR tool. They can be further explored in this aspect.

\section{CONCLUSION}

The knowledge transfer in the class room from the teacher to the students plays an important role in the teaching learning process. This can be achieved by keeping the discussion more interactive and innovative. This is evident when using the $\mathrm{CM}$ in the class room. During this study, basics of CM were introduced and a test was conducted. The participants were asked to create maps, representing their understanding the concepts taught during the session. The maps were scored and the results were analyzed and found to be encouraging for further studies to assess the impact of using CM as KR tool in the educational settings. Thus this paper concludes with the remark that the CMs can be utilized as a KR tool to teach, learn concepts and evaluate the understanding of the learners. Further studies are needed to analyze the role of $\mathrm{CM}$ as an assessment tool in other aspects under different environments. The authors also like to mention that the future works would be; (i) developing automatic evaluation of CMs would be potential research issue (ii) using the $\mathrm{CM}$ in e-learning context with select processes and rigorous exploration to underpin the impact of CM (iii) to design and implement a CM based framework that would serve select teaching learning process for specific course. 


\section{REFERENCES}

[1] Joseph D. Novak \& Alberto J. Canas, "The Theory Underlying Concept Maps And How To Construct And Use Them", Institute For Human And Machine Cognition, 2006.

[2] Novak, J. D., \& Gowin, D. B., "Learning How To Learn", New York And Cambridge, Uk: Cambridge University Press.1984.

[3] Novak, J. D, "Concept Maps And Vee Diagrams: Two Meta Cognitive Tools For Science And Mathematics Education”. Instructional Science, 19, 1990, Pp 29-52.

[4] Novak, J. D, "How Do We Learn Our Lesson?: Taking Students Through The Process". The Science Teacher, 60(3)1993, pp 51-55.

[5] K.C. Gupta, R. Ramadoss, And H.Zhang, "Concept Mapping And Concept Modules For Web-Based CDROM - Based RF And Microwave Education", IEEE Trans. Microwave Theory Tech., Vol. 51, Mar 2003, pp $1306-1311$.

[6] Debopriyo Roy, "Concept Map-Oriented Technical Writing Approach For Computer Science Majors in an EFL Context: Understanding Text Applications", Proc. Of Ieee Intl. Professional Communication Conference (IPCC) 2010, pp 67 - 79.

[7] Gul Takdemir And Nergiz Ercil Cagiltayet, "A Concept Map Approach For Introduction To Computer Course Curriculum", Proceedings of IEEE Educon Education Engineering 2010 - The Future of Global Learning Engineering Education,2010, pp 243-250.

[8] Guliz Aydin, Ali Gunay Balim, "Technologically Supported Mind And Concept Maps Prepared By Students On The Subjects Of The Unit 'Systems In Our Body"', World Conference On Educational Sciences 2009, Procedia Social And Behavioral Sciences ,2009, pp 2838-2842.
[9] H. Omer Beydogan, Gursel Bayindir, "Effect of Concept Map Supported Teaching Approaches From Rules To Sample And Sample To Rules To Grammar Teaching", Procedia Social And Behavioral Sciences 2, 2010, pp 3954-3964.

[10] Mehmet Buldu, Nihal Buldu, "Concept Mapping As A Formative Assessment In College Classrooms: Measuring Usefulness And Student Satisfaction", Science Direct, Procedia Social And Behavioral Sciences 2, 2010, pp 2099-2104

[11] Julia Alonso Delgado and Carlos Araya Rivera, "Concept Mapping as an Assessment Tool in Higher Education Activities", Proc. of the Third Intl. Conference on Concept Mapping, Finland 2008.

[12] Mehmet Fatih Oçal, Gursel Guler, "Pre-Service Mathematics Teachers' Views About Proof By Using Concept Maps", Procedia Social and Behavioral Sciences 9, 2010, pp 318-323.

[13] Mine Taskin, "The Effect Of Concept Maps In Teaching Sportive Technique" Procedia Social and Behavioral Sciences 11, 2011, pp 141-144.

[14] Mintzes J, Wandersee J, \& Novak, J,“Assessing Science Understanding”. San Diego: Academic Press.1999.

[15] Nosek, J. T. \& Roth, I., "A Comparison Of Formal Knowledge Representation Schemes As Communication Tools: Predicate Logic Vs. Semantic Network", International Journal Of Man-Machine Studies 33, 1990, pp 227-239.

[16] Rob Kremer, "Visual Languages for Knowledge Representation", KAW'98: Eleventh Workshop on Knowledge Acquisition, Modeling and Management, Voyager Inn, Banff, Alberta, Canada, 1998.

[17] Edwards, J., \& Fraser, K., "Concept Maps as Reflections of Conceptual Understanding", Research in Science Education, 1983, pp 19-26. 